\title{
Physician Collective Bargaining
}

\author{
Anthony Hunter Schiff JD, MPH
}

Published online: 12 September 2009

(C) The Author(s) 2009. This article is published with open access at Springerlink.com

\begin{abstract}
Current antitrust enforcement policy unduly restricts physician collaboration, especially among small physician practices. Among other matters, current enforcement policy has hindered the ability of physicians to implement efficient healthcare delivery innovations, such as the acquisition and implementation of health information technology (HIT). Furthermore, the Federal Trade Commission and Department of Justice have unevenly enforced the antitrust laws, thereby fostering an increasingly severe imbalance in the healthcare market in which dominant health insurers enjoy the benefit of largely unfettered consolidation at the cost of both consumers and providers. This article traces the history of antitrust enforcement in healthcare, describe the current marketplace, and suggest the problems that must be addressed to restore balance to the healthcare market and help to ensure an innovative and efficient healthcare system capable of meeting the demands of the 21 st century. Specifically, the writer explains how innovative physician collaborations have been improperly stifled by the policies of the federal antitrust enforcement agencies, and recommend that these policies be relaxed to
\end{abstract}

Each author certifies that he or she has no commercial associations (e.g., consultancies, stock ownership, equity interest, patent/licensing arrangements, etc) that might pose a conflict of interest in connection with the submitted article.

\section{A. H. Schiff $(\bowtie)$}

1875 Century Park East, Suite 1600, Los Angeles,

CA 90067, USA

e-mail: tschiff@mdhealthlaw.com

A. H. Schiff

UCLA School of Public Health, Los Angeles, CA, USA

A. H. Schiff

Schiff \& Bernstein, APC, Los Angeles, CA, USA permit physicians more latitude to bargain collectively with health insurers in conjunction with procompetitive clinical integration efforts. The article also explains how the unbridled consolidation of the health insurance industry has resulted in higher premiums to consumers and lower compensation to physicians, and recommends that further consolidation be prohibited. Finally, the writer discusses how health insurers with market power are improperly undermining the physician-patient relationship, and recommend federal antitrust enforcement agencies take appropriate steps to protect patients and their physicians from this anticompetitive conduct. The article also suggests such steps will require changes in three areas: (1) health insurers must be prohibited from engaging in anticompetitive activity; (2) the continuing improper consolidation of the health insurance industry must be curtailed; and (3) the physician community must be permitted to undertake the collaborative activity necessary for the establishment of a transparent, coordinated, and efficient delivery system.

\section{Introduction}

The antitrust laws are "a consumer welfare prescription" [1]. They ensure competition and prohibit restraints on trade that lead to higher prices, reduced quality, or injury to market efficiencies for inputs such as hospital and physician services $[2,3]$.

Several antitrust statutes have application in the healthcare area. A key federal statute for physicians is Section 1 of the Sherman Act (15 U.S.C. \$1), which provides:

"Every contract, combination in the form of trust or otherwise, or conspiracy, in restraint of trade or 
commerce among the several states, or with foreign nations, is declared to be illegal."

Large health insurers must also be required to comply with the statutes involving mergers and monopolization. Section 7 of the Clayton Act (15 U.S.C. §18) prohibits mergers that may "substantially...lessen competition, or...tend to create a monopoly." Section 2 of the Sherman Act makes it unlawful for a company to "monopolize, or attempt to monopolize" trade or commerce.

Because of the important economic underpinnings reflected in the antitrust laws, penalties for violating them are severe. Criminal violations of the Sherman Act are felonies punishable by imprisonment for up to 3 years and/ or fines of up to $\$ 350,000$ for individuals and $\$ 10$ million for corporations per violation (15 U.S.C. \$1). A criminal conviction virtually assures civil liability. Judgments for civil violations often run in the millions of dollars, particularly because a private party can recover three times the amount of damages actually sustained, as well as other costs and attorneys' fees incurred in prosecuting the action-fees which often exceed \$1 million.

This article traces the history of antitrust enforcement in health care, which has often harmed physicians while at the same time greatly benefited health insurers. The discussion then turns to the health care marketplace in 2009, and documents four major factors that compel a need to revisit antitrust enforcement policy: (1) uncontrolled health insurer consolidation and market power; (2) healthcare workforce shortages; (3) the rising disparity between increasing physician practice costs and flat or declining reimbursements; and (4) the demand for investments in health information technology. Finally, the discussion turns to potential remedies for the imbalance in the marketplace between health insurers and physicians, including changes in antitrust enforcement policy to curtail continued health insurer consolidation and prohibit anticompetitive conduct by health insurers with market power on the one hand, while relaxing the rules applicable to physicians to permit procompetitive collaborations necessary for the optimal implementation of health information technology and other innovations necessary to an efficient health care delivery system.

\section{Physicians and the Antitrust Laws}

For many years, the general consensus was that the professions were immune from the antitrust laws. However, in 1975 the landscape changed dramatically when the U.S. Supreme Court issued its opinion in the case of Goldfarb v. Va. State Bar [4], in which the high court concluded that the antitrust laws applied to attorneys, and every other profession, stating that the "nature of an occupation, standing alone, does not provide sanctuary from the Sherman Act... nor is the public-service aspect of professional practice controlling in determining whether $\$ 1$ includes professions." Any doubt as to whether physicians were covered by the Goldfarb decision was eliminated in Arizona v. Maricopa County Medical Society [5], where the U.S. Supreme Court found that an agreement among physicians to set maximum prices charged by those who participated in a PPO network constituted a per se violation of the Sherman Act. Under the per se rule, the practice is deemed so manifestly anticompetitive in nature that it is deemed illegal, without regard to its actual market impact. Under the "rule of reason," the standard more commonly applied to an antitrust challenge, the anticompetitive consequences of a challenged practice are weighed against its purpose and procompetitive effect.

Unfortunately, the Maricopa decision went much farther than just to confirm that physicians were subject to the antitrust laws. It applied the per se rule to outlaw a joint contracting activity - the agreement to a maximum feeschedule-that was arguably necessary to the maintenance of a physician network. Yet, as the proliferation of the rental network PPO market has demonstrated, physician rental networks clearly have a place in the healthcare delivery system. Indeed, the Maricopa case came to the Supreme Court in response to a request by the State of Arizona for an early legal ruling that an agreement between competitors to set maximum prices was illegal per se, just as an agreement between competitors to set minimum prices had long been declared to be flatly illegal. The parties to the case had engaged in only limited discovery by the time of this request, so there was no factual record before the U.S. Supreme Court on the potential efficiencies of physician joint contracting. Thus, it should not be surprising that the decision is in tension with other U.S. Supreme Court cases holding similar joint arrangements in other industries to be subject to the so-called rule of reason [6], or that Maricopa was a 4-3 decision.

The application of the antitrust laws to physicians has continued to be the subject of concern since the overly broad Maricopa decision. Responding to concerns that the antitrust laws were unduly stifling healthcare innovation, the Federal Trade Commission (FTC) and Department of Justice (DOJ) jointly issued Statements of Enforcement Policy in Health Care (the "Statements") during the 1990s in an effort to provide clearer guidance as to those activities the agencies would (or would not) find problematic. While these Statements are not binding on the courts, they are important reflections of FTC/DOJ enforcement priorities.

The initial version of the Statements was released in September 1993 and contained eight separate policy 
statements, including Statement 8 on "Physician Network Joint Ventures" [7]. Reflecting the Maricopa decision, Statement 8 identified two features of particular importance: (1) the network's percentage or "share" of the physicians in each physician specialty practicing in the relevant geographic markets; and (2) whether the physicians had integrated their practices by sharing "substantial financial risk." Only the sharing of "substantial financial risk" was sufficient to allow a network to be evaluated under a reasonableness standard. Other forms of integration-structural, functional, or transactional-were not considered adequate to avoid per se condemnation.

According to the Statements, sharing "substantial financial risk" could be accomplished in one of two ways: (1) by accepting "capitated" or "per-member per-month" payments; or (2) by incentivizing physicians to contain costs through the use of a substantial withhold from payments. The existence of either type of substantial financial risk meant that the physician collaboration, if challenged, would be evaluated under the rule of reason standard. The absence of any evidence of substantial financial risk would result in summary condemnation of the collaboration as per se illegal price fixing [7]. As noted above, per se illegality conclusively presumes the challenged practices unreasonable. In other words, when a per se offense, like price fixing among competitors, is charged, all that must be established is that the defendant has, in fact, engaged in the proscribed practice.

With the rapid expansion of managed care in the 1990s, the requirement of financial risk-sharing as the defining feature of a legitimate physician network proved to be unduly restrictive. In many regions of the country, physician capitation proved to be an unpopular and highly controversial payment methodology. Employers wanted broad networks that allowed patients a broad choice among physicians, without perceived incentives to withhold or ration care. Yet, the definition of "substantial financial risk" adopted by the agencies creates a significant barrier to the participation of physician-led contracting networks.

In the 1996 version of the Statements, the agencies recognized a second type of integration that could qualify a physician network for rule of reason treatment- "Clinical Integration." Clinical integration, as defined in the Statements, is evidenced "by the network implementing an active and ongoing program to evaluate and modify practice patterns by the network's physician participants and create a high degree of interdependence and cooperation among the physicians to control costs and ensure quality" [8]. Clinical integration as so defined represented a sort of "as if" standard, i.e., a physician network that acted "as if" its members shared financial risk-by instituting the types of efficiencies associated with financial risk sharingmight qualify for rule of reason treatment despite the absence of "substantial financial risk." For several years following the publication of the 1996 Statements, the agencies gave no further guidance on the meaning of clinical integration.

In 2002, however, the FTC issued a staff advisory letter addressing the clinical integration proposal of MedSouth, Inc., an independent practice association based in Denver, CO, with over 400 physicians [9]. And in 2007, the FTC issued a similar staff advisory letter to the Greater Rochester Independent Practice Association, Inc. (GRIPA), a network based in Rochester, NY, with over 600 physician members [10]. The MedSouth and GRIPA letters demonstrate how high the bar has been set for physician networks seeking to integrate clinically. While the MedSouth and GRIPA proposals are not identical, they bear substantial similarities. Both networks were originally built for capitation, but needed to adapt in the face of market resistance. Thus, both MedSouth and GRIPA were constructed "as if" the physicians were sharing substantial financial risk. Only when risk contracting proved to be commercially infeasible did the networks seek FTC approval for their clinical integration programs. Both MedSouth and GRIPA made major investments, using myriad consultants, lawyers, and technology experts to assist in the effort. Both networks invested in electronic medical records and tracking technology to permit their network physicians to share information on their patients and to monitor data relating to utilization and medical outcomes. Both networks developed clinical practice guidelines and procedures for monitoring compliance, and both networks were "nonexclusive," meaning that payors choosing not to support the clinically integrated program would not lose access to any desirable physicians who were participating in the network. Importantly, the FTC found no anticompetitive motivation for either network.

Despite the substantial investment of resources, neither MedSouth nor GRIPA achieved FTC approval easily or without significant ongoing conditions and caveats. Both FTC advisory letters reflected extensive agency investigation of the networks' history, purposes, contracting mechanisms, disciplinary methods for noncompliant physicians, and strategies for producing efficiencies. Each investigation involved a searching examination of the so-called "ancillarity" [11] of the networks' pricing mechanisms to its efficiency-enhancing potential. Ancillarity refers to whether a pricing mechanism is "reasonably related to the integration and reasonably necessary to achieve its pro-competitive benefits." Each letter also left the FTC plenty of room to bring a later enforcement action if the networks' operations could not later be shown to produce substantial efficiencies.

The MedSouth and GRIPA advisory letters reflect the extremely high level of clinical integration required for 
FTC approval. As a practical matter, absent vast resources, such as those available to MedSouth and GRIPA, most physicians are effectively barred from forming physician networks. Unfortunately, unless they are employed in an integrated medical group, physicians cannot work collaboratively on costly and complex healthcare quality initiatives nor participate in balanced negotiations with health insurers without such networks.

Outside the healthcare context, courts and the federal agencies themselves appear to apply a more flexible analysis than that found in the Statements. For example, in the Joint FTC/DOJ Guidelines on Competitor Collaboration, there is no mention of financial or clinical integration. Instead, the Competitor Collaboration Guidelines ask more generally whether a joint venture involves "an efficiencyenhancing integration of economic activity" and whether any restraints are "reasonably related to the integration and reasonably necessary to achieve its pro-competitive benefits" [12]. The Supreme Court, too, in its joint venture cases has rejected any fixed formulation of what may constitute integration sufficient to warrant rule of reason treatment [6].

\section{Health Insurers and the Antitrust Laws}

Health insurers, like physicians, were originally thought to be immune from the antitrust laws. This changed in 1944 when the U.S. Supreme Court ruled in United States v. South-Eastern Underwriters Association [13] that Congress had the power to regulate insurance companies, despite the then prevailing view that "insurance is not commerce." However, unlike physicians, insurers were successful in reinstating much of their prior immunity the next year when Congress enacted the McCarran-Ferguson Act. Under that Act, the federal antitrust laws do not apply to the "business of insurance" as long as the state regulates in that area, except in cases of boycott, coercion, and intimidation.

While the precise scope of the McCarran-Ferguson Act immunity remains unclear, it is not absolute, particularly when it comes to merger challenges. Because health insurers are both sellers of insurance to consumers and buyers of medical services, mergers and other conduct involving health insurers potentially can raise issues related to both monopoly (only one seller) power and monopsony (only one buyer) power. As discussed below, health insurers have entered into consent decrees with respect to certain mergers.

The 1992 Horizontal Merger Guidelines ("Merger Guidelines") specify that "mergers should not be permitted to create or enhance market power or to facilitate its exercise" [14]. As with the FTC/DOJ Statements, these Merger Guidelines do not bind courts, but they do describe the Agencies' enforcement priorities. Market power "is the ability profitably to maintain prices above competitive levels for a significant period of time" [14 at n.9]. A merger also may "lessen competition on dimensions other than price, such as product quality, service, or innovation" [14 at n.6].

To identify mergers that are likely to cause competitive problems, the Merger Guidelines provide for the examination of several issues, including: whether the merger, in light of market concentration and other factors that characterize the market, would be likely to have adverse competitive effects; whether entry would be timely, likely, and sufficient either to deter or to counteract the competitive effects of concern; whether there are efficiency gains from the merger that meet the Agencies' criteria for examination; and whether, but for the merger, either party to the transaction would be likely to fail, causing its assets to exit the market [14 at $\$ 0.2]$.

As discussed below, the health insurance market in the United States is now highly concentrated. While the new administration may institute change, to date the FTC and DOJ have shown little interest in restricting additional mergers, and no interest in addressing complaints of monopolization by dominant health insurers.

\section{The Current Healthcare Market}

Over the past several years, healthcare market conditions have changed in major ways that suggest a need to revisit the antitrust landscape. Health insurers have consolidated to the point that the ability of physicians to advocate on behalf of their patients and themselves has been severely compromised. At the same time, and exacerbated by this imbalance, shortages of healthcare providers are becoming increasingly acute, as discussed in detail below. Simultaneously, the aging population is creating a greater demand for healthcare services. Finally, market and regulatory developments are increasingly placing a premium on the use of HIT and the measurement and improvement of medical care.

While beyond the scope of this paper, the writer notes that community hospitals have also been impacted by predatory contracting tactics employed by the insurance industry. Required by state law to maintain licensed services, including skilled nursing, and burdened by technology cost outlays, community nonprofit hospitals have been very vulnerable to predatory contracting tactics. And like physicians, hospitals are prohibited from engaging in collective bargaining. As a result, these hospitals have in many instances downsized or gone out of business, leaving the public more vulnerable to pandemics and other natural disasters and emergencies. 


\section{Uncontrolled Health Insurer Market Power and Consolidation}

The health insurer market has changed substantially due to a wave of mergers over the past decade, steadily eroding the competitive payor market [15]. In fact, during the last decade, there have been over 400 health insurer mergers. Tellingly, only three mergers have been challenged by the DOJ. As a result, the payor market has consolidated and payors enjoy substantial negotiating leverage over providers in most markets. The AMA has just completed the 2008 edition of its publication tracking the consolidation of the health insurance industry entitled "Competition in health insurance: A comprehensive study of U.S. markets" [16]. In this most recent study, the AMA found that $94 \%$ of the Metropolitan Statistical Areas (MSAs) it examined are highly concentrated using standards relied on by the federal antitrust enforcement agencies. Further, in $89 \%$ of those MSAs, a single health insurer holds at least $30 \%$ of the market for commercial health insurance [16].

To put this in perspective, in 2000, the two largest health insurers, Aetna and UnitedHealth Group ("United"), had a total combined membership of 32 million people. Due to aggressive merger activity since 2000, including United's acquisition of California-based PacifiCare Health Systems, Inc., and John Deere Health Plan in 2005, United's membership alone has grown to 33 million. Similarly, WellPoint, Inc. ("Wellpoint"), the company born of the merger of Anthem, Inc. (originally Blue Cross Blue Shield of Indiana), and WellPoint Health Networks, Inc. (originally Blue Cross of California), now owns Blue Cross plans in 14 states, covering approximately 34 million Americans [17]. Most recently, United acquired Sierra Health Systems in Nevada, allowing United to acquire over 50 percent of the Nevada market, including a 90 percent share of the health maintenance organization ("HMO") market.

The power garnered by health insurers through rapid, large-scale consolidation has not been used to the advantage of consumers or providers. Patient premiums have soared in this increasingly consolidated market and physician reimbursement has decreased. As premiums have risen, many employers have stopped providing coverage; particularly those firms with three to nine employees [18], substantially limited or reduced the scope of benefits provided, and/or asked employees to pay a higher share of the overall premium, thus effectively shrinking the scope of coverage. The 2008 Kaiser Family Foundation survey found that large firms (classified as having 200 or more workers) provide $99 \%$ of their full time employees with health insurance, as opposed to $40 \%$ in firms with 3-9 employees. This figure was 56\% for small firms in 1999 . As of 2006, premiums for employer-based health insurance rose more than twice as fast as overall inflation and wages for the seventh straight year [19]. Since 2000, the amount that workers pay toward family healthcare coverage has skyrocketed 84\% [19] and 5 million fewer workers were receiving job-based coverage in 2006 than in 2000 [19]. During the same period, average wages increased only $20 \%$ [19]. These soaring costs have directly contributed to an increase in the number of uninsured. Research shows that a $1 \%$ increase in premiums results in a net increase in the uninsured of 164,000 individuals [20].

Nor have physicians benefited from these premium increases. To the contrary, powerful insurers have depressed physician revenues [21]. The median real income of all U.S. physicians remained flat during the 1990s and has since decreased [22]. The average net income for primary care physicians, after adjusting for inflation, declined $10 \%$ from 1995 to 2005, and the net income for medical specialists declined $2 \%$ [22].

This reduction in physician income has not benefited patients, and indeed may have harmed them. The phenomenon of lower physician fees paid by insurers potentially resulting in higher prices to patients was emphasized by R. Hewitt Pate, a former Assistant Attorney General of the Antitrust Division, in a statement before the Senate Judiciary Committee:

"A casual observer might believe that if a merger lowers the price the merged firm pays for its inputs, consumers will necessarily benefit. The logic seems to be that because the input purchaser is paying less, the input purchaser's customers should expect to pay less also. But that is not necessarily the case. Input prices can fall for two entirely different reasons, one of which arises from true economic efficiency that will tend to result in lower prices for final consumers. The other, in contrast, represents an efficiencyreducing exercise of market power that will reduce economic welfare, lower prices for suppliers, and may well result in higher prices charged to final consumers."

Health plan executives and shareholders, on the other hand, have reaped enormous monopoly profits [23]. The profit margins of the major national firms experienced double-digit growth between 2001 and 2008 [23 at pp. 19-20]. United and WellPoint, specifically, had 7 years of consecutive double-digit growth that has ranged from $20 \%$ to $70 \%$ year after year (through 2003) [23 at pp. 19-20].

In addition to affecting costs, payments, and profits, this consolidation has created an extreme imbalance in health insurer-physician contracting that threatens all aspects of patient care. Health insurers are able to dictate important aspects of patient care and material contract terms to 
physicians that intrude into medical care decisions [18 at p.5]. Physicians have little to no ability to influence insurer contracts that touch on virtually every aspect of the patientphysician relationship. Many contracts are essentially "contracts of adhesion"- -standardized contracts that are submitted to a weaker party on a take-it or leave-it basis and do not provide for negotiation. This means that physicians must agree to contracts that often include provisions that make it difficult, if not impossible, for them to promote what they deem to be the optimal patient care. For example, many contracts define "medically necessary care" in a manner that allows the health insurer to overrule the physician's medical judgment and require the lowest cost, but not necessarily optimal, care for the patient. Others require compliance with undefined "utilization management" or "quality assurance" programs that often are nothing more than thinly disguised cost-cutting programs that penalize physicians for providing care they deem necessary. Some have gone so far as to require the physician to suffer a significant financial penalty if the physician fails to use a designated setting for services, even when the use of that setting would jeopardize the patient's health or impose a substantial hardship.

These contracts also often dictate key financial terms in ways that no supplier of services in any other industry sector would tolerate. For example, these contracts may refer to "fee schedules" that are never provided and can be revised unilaterally by the health insurer. Many contracts allow the health insurer to change any term of the contract unilaterally. These contracts also frequently contain such unreasonable provisions as "most favored payor" clauses-clauses requiring physicians to bill the dominant health insurer at a level equal to the lowest amount the physician charges any other health insurer in the region. This permits the dominant health insurer to guarantee that it will have the lowest input costs in the market, making it that much more difficult for new payors to enter the market. They also contain "all products" clauses-clauses requiring physicians to participate in all products offered by a health insurer as a condition of participation in any one product. This often includes the health insurer reserving the right to introduce new plans and designate a physician's participation in those future plans. Given the rapid development of new products and plans, the inability of physicians to select which products and plans they want to participate in makes it difficult for physicians to manage their practices effectively.

Despite the improper restrictions and potential dangers of these contracts, the current imbalance in the market dictates that physicians typically have no choice but to accept them. Any alleged "choice" is illusory given that choosing to leave the network often means terminating patient relationships and drastically reducing or losing one's medical practice. In my experience, the strong personal relationships physicians form with their patients often influence them to accept contract terms that they would not accept but for those personal bonds. In addition, because medical services cannot be stored or exported, physicians have limited options for selling their services. If physicians were to refuse the terms of a major health insurer, they would likely suffer a significant loss. Consequently, a physician's ability to terminate a relationship with a health insurer depends on that physician's ability to make up for the loss by switching to an alternative insurer, or other purchasers of the physician's services.

Where alternative purchasers are lacking, physicians are forced to accept unfair contracts. The DOJ, in its 1999 challenge of the Aetna/Prudential merger recognized that there are substantial barriers to physicians expeditiously replacing lost revenue by changing health plans. It also noted that this imposes a permanent loss of revenue [24]. The DOJ reiterated this position in its challenge to the UnitedHealth Group/PacifiCare merger [25]. Furthermore, even where there are other insurers, physicians are limited in their ability to encourage patients to switch plans, as patients can typically switch employer-sponsored plans only during the once a year open enrollment period, and even then, patients have limited options and may incur considerable out-of-pocket costs should they wish to change insurers to follow their physicians [25].

In this environment, the antitrust enforcement agencies need to do far more to protect competition in health insurer markets. The continued enforcement focus on physician collaboration efforts is inappropriate given the scant likelihood in most payor-dominated markets that physician networks would be able to exercise market power in their negotiations with insurers. The brutal fact is that health insurers are aware that given the cost of office overhead, the vast majority of physicians must contract with all major payors if they are to remain viable, no matter how unreasonable the contract terms.

\section{Healthcare Workforce Shortages}

The problems described above have exacerbated the physician workforce shortage. The Association of American Medical Colleges (AAMC) publication "The Complexities of Physician Supply and Demand: Projections Through 2025" released in October 2008 highlights that the United States faces an increasing physician workforce shortage [26]. Numerous factors such as an aging population which requires more health resources and a growing population create added future demand on the US health system. On the supply side, key factors, including that (1) one-third of the active physicians $(250,000)$ are over age 55 years and 
likely to retire by 2020; and (2) the newest generation of physicians may be unwilling to work the extraordinarily long hours that prior generations of physicians routinely worked, will add additional strains to this expected physician supply dilemma [27].

A brief discussion of the current and projected demand for physician services is illustrative of the problem. The U.S. Census Bureau projected the 2006 U.S. population would be approximately 300 million. Medical care was provided to this population by 256,500 FTE general primary care physicians (general and family practice, general internal medicine, and general pediatrics); 90,900 FTE medical specialty physicians (cardiovascular disease, gastroenterology, internal medicine subspecialties, nephrology, pulmonology, and other medical specialties); 142,400 FTE surgeons (general surgery, obstetrics and gynecology, ophthalmology, orthopedic surgery, otolaryngology, thoracic surgery, urology, and other surgical specialties); and 190,800 FTE physicians classified as other patient care (anesthesiology, emergency medicine, neurology, pathology, psychiatry, radiology, and other specialties) [26]. In 2025, the U.S. population is projected to be 350 million. This population will receive medical care from an estimated 272,700 FTE general primary care physicians, 117,600 FTE medical specialty physicians, 138,800 FTE surgeons and 205,700 FTE physicians classified as other patient care [26]. The AAMC predicts these modest increases in physician supply will be inadequate to meet the needs (Fig. 1).

Recognizing that the expansion of U.S. medical school capacity will require 10 or more years, the AAMC has recommended a $30 \%$ increase in U.S. medical school enrollment and an expansion of Graduate Medical Education (GME) positions to accommodate this growth [28]. Nonetheless, with the baby boom generation entering retirement, and the extensive academic and clinical time required to produce physicians, simply educating and

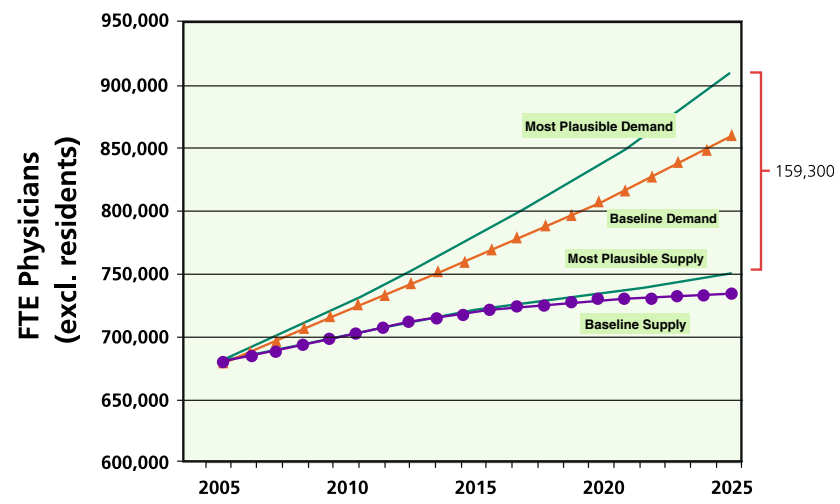

Fig. 1 A projection of numbers of FTE physicians 2006-2025 suggests the number will be inadequate. (C) 2008 Association of American Medical Colleges. All rights reserved. Reproduced with permission.) training more physicians will not be enough to address these shortages. Additional and complex changes to improve efficiencies, to reconfigure health service delivery, and to better use of the nation's physicians will also be needed. But change of this magnitude requires flexibility and resources.

\section{Increasing Disparity between Practice Costs and Reimbursements}

Further compounding the problem is the accelerating disparity between the increases in physician practice costs and the flat or declining payments physicians are receiving for their services. This problem is most acute with respect to the Medicare fee schedule, as currently impacted by the misnamed "Sustainable Growth Rate" (SGR) (Fig. 2).

Indeed, the chart below depicts a conservative picture of the problem, as the physician cost data graphed on this chart is from the government's Medicare Economic Index. The physician practice cost surveys conducted by the Medical Group Management Association suggest that the inflation rate in physician practice expenses is far greater (Fig. 3).

\section{Consumerism and Health Information Technology (HIT)}

Another ongoing and major change in the healthcare market is the shift towards consumerism and the concomitant demand for more accessible health information. There

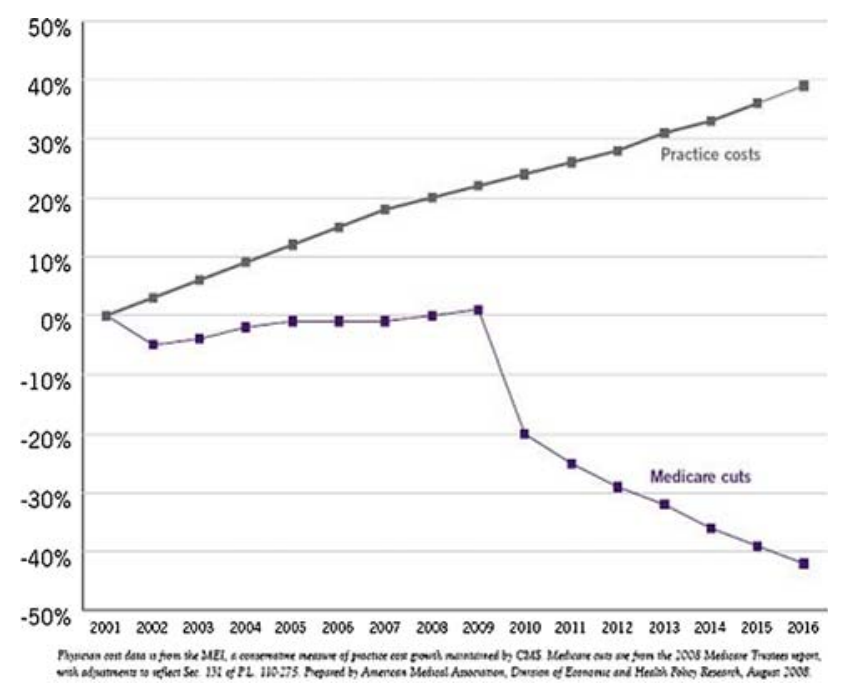

Fig. 2 Physician costs and Medicare reimbursement (abscissa) over time; there is a projected increase in the gap. (Prepared by the American Medical Association, Division of Economic and Health Policy Research.) (@ 2008 American Medical Association. All rights reserved. Reproduced with permission.) 
Fig. 3 Cumulative percent change since 2001 for the Medicare conversion factor, multispecialty group operating cost and the consumer price index medical group management association 2008. (C) 2008 Medical Group Management Association. Reprinted with permission.)

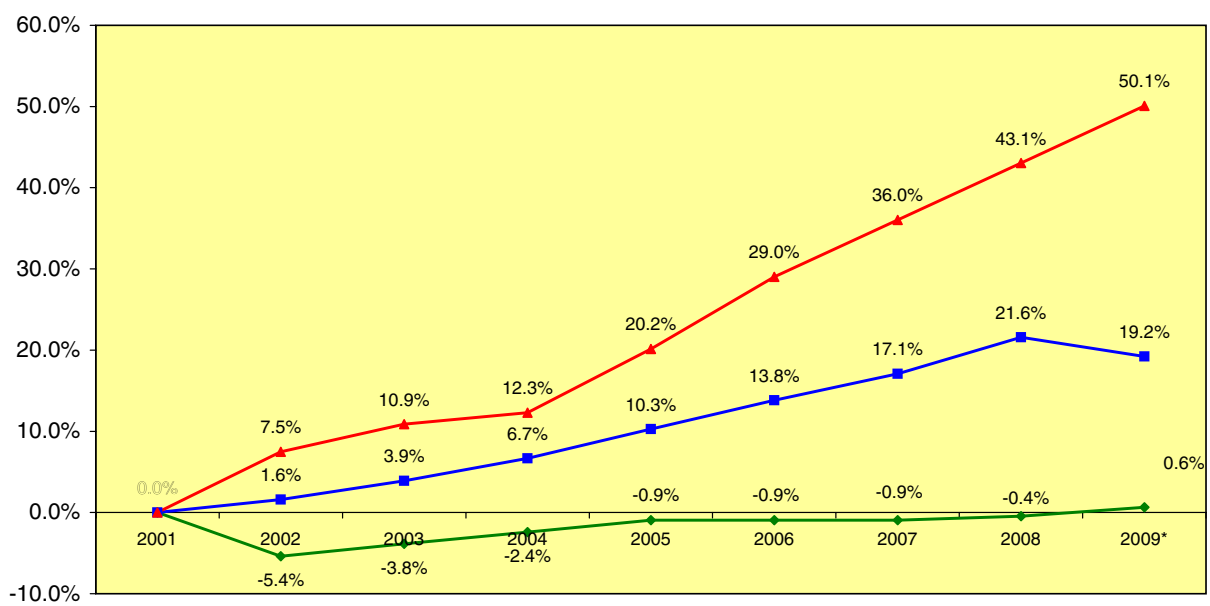

*2009 Data includes the CPI as of January 2009 and projected change in operational costs as occurred 2007-2008.

$\curvearrowleft$ Medicare Conversion Factor $\rightarrow$ CPI $\rightarrow$ Total Operating Cost per FTE Physician are increasingly focused efforts on developing methods of promoting and measuring quality. At the same time, the federal government is seeking to encourage physicians and other providers to invest in HIT to facilitate the collection and sharing of clinical data. On the payor side, employers are favoring health plans that put increasing responsibility on patients to participate actively in choosing (and paying for) care. For physicians, who still practice predominantly in small groups, network arrangements provide a viable way of achieving the economies of scale necessary to participate in these initiatives, where optimal use of the integrative potential of the technology requires substantial capital and coordinated decision-making [29].

The shift towards performance-based reimbursement provides a good example of the strong incentives for physicians to collaborate with one another to collect and analyze quality data. "Pay-for-performance" (P4P) reimbursement is "now routinely used by both private and public payors in the U.S. healthcare system" [30]. A majority of commercial HMOs use $\mathrm{P} 4 \mathrm{P}$ and recent legislation requires Medicare to adopt performance-based incentives [31]. As the adoption of P4P spreads and its use expands, physicians in small practices will be increasingly motivated to align with networks in order to have the capability to participate in these programs. However, and despite the potential for such arrangements to enhance efficiency, networking among physicians will not proliferate in the absence of a change in current antitrust enforcement policies.

\section{Potential Remedies to the Current Malaise}

As the preceding discussion illustrates, the profound imbalance in the marketplace between the health insurers who collect premiums to pay for medical care and the physicians who provide medical care, has resulted in an increasingly unfair and inefficient healthcare delivery system. The playing field between health insurers and physicians must be leveled to remedy the situation and restore the true competition and creativity that are sorely needed to ensure all Americans have access to affordable, quality medical care. This will require changes in three areas: (1) health insurers must be prohibited from engaging in anticompetitive activity; (2) the continuing improper consolidation of the health insurance industry must be curtailed; and (3) the physician community must be freed to undertake the collaborative activity necessary for the establishment of a transparent, coordinated, and efficient delivery system.

\section{Prohibit Health Insurers from Engaging in Anticompetitive Activity}

Health insurers throughout the country have amassed substantial market power and must be prohibited from exercising that power in ways that are anticompetitive. It is not clear that new laws are required to accomplish this; there are already many laws at both the federal and state levels that could be deployed for this purpose. Rather, it appears that the principle change required is a reevaluation of the premise apparently shared by most antitrust enforcers that health insurers consistently act as surrogates for consumers. As the prior discussion indicates consumers as well as physicians have suffered as ever more powerful health insurers have increased both premiums and profits. Predatory conduct by health insurers is at least as bad for consumer welfare as predatory conduct which occurs in other industries. If anything, prosecutorial 
discretion should be exercised more aggressively in this market, particularly given the lack of accountability that this sector has enjoyed.

Curtail the Continuing Consolidation of the Health Insurance Industry

For the reasons discussed above, it is also critical that the health insurance industry not be allowed to become further consolidated. Again, there appear to be laws at both the federal and state levels to preclude further consolidation in any circumstance where the effect of the consolidation will be to lessen competition. The principal problem appears to be a failure of enforcement. However, given their focus on and expertise with health insurance, it does appear that state insurance commissioners could play a more important role in this area.

Permit Physicians to Participate in Procompetitive Collaborations

Finally, antitrust enforcement policies directed at physicians must be reevaluated. Joint contracting by physicians in a network can result in extensive collaboration to improve and measure care and to provide cost savings for both payors and physicians. On the payor side, joint contracting can make it possible for a payor to obtain ready access to a panel of physicians offering broad geographic and specialty coverage [32]. Since physicians still practice predominantly in solo or small group practices, creating a physician panel can be a very time-consuming and expensive task, and can be a barrier to entry or expansion for new or less significant insurers. In its complaint in United States v. Aetna, the DOJ noted that "effective new entry for an HMO or HMO/POS plan in Houston or Dallas typically takes 2 to 3 years and costs approximately $\$ 50,000,000 "$ [24]. When the physicians themselves undertake the initial task of network formation, payors may substantially reduce the costs of the payors' entry and expansion. Indeed, any doubt concerning the intrinsic efficiency of physician networks should be eliminated by the thriving rental PPO network business that has emerged to supplement inadequate networks. Joint contracting thus has the potential both to reduce costs for payors and to increase competition in payor markets. These are cognizable benefits, with real potential to create efficiencies, lower premiums and expand coverage for patients.

Joint contracting can also make physician contracting more efficient and lead to better-informed contracting decisions. Most physician practices are simply too small to afford to hire business advisers and lawyers to review their contracts with payors. These physician practices do not have the in-house resources to analyze complex contracts. Whereas payors have sophisticated actuarial and financial resources that enable them to structure and evaluate complex contract proposals, physicians are often in the dark when they consider a contract. By pooling their resources, physicians can spread the costs associated with the analysis of payor contracts, and develop appropriate counteroffers that can benefit patient, physicians, and payors. The effect is to enhance the efficiency of the physicians' practices and make them more responsive to the demands of competition.

Likewise, joint contracting can provide the resources physicians need for creating networks that will facilitate collaboration on HIT. The benefits of HIT fall into two basic categories. First, the system may reduce the costs of running a medical practice. For example, it can eliminate the need to archive and store medical records. Medical records are rarely lost and communication between physicians is enhanced and preserved. Second, these systems can create cost savings by increasing the availability of patient data and, correspondingly, by eliminating the duplication of services to patients. For instance, HIT may reduce the frequency of primary and specialty physicians ordering the same test. Currently, however, physicians are unable to capture the financial returns or substantial benefits from HIT that are necessary to offset the high implementation costs. Today, those benefits and financial returns accrue mainly to health insurers, rather than physicians. Thus, it is unlikely, as noted by the Congressional Budget Office, that a solo practitioner or a small group practice will realize any real, internal cost savings from information technology systems [33].

This is a classic problem recognized in economics-the problem of externalities. An externality arises when an individual cannot recover the costs of investing in an asset because most of the benefits fall to an individual whom the investor has no way of charging for the benefit. Building roads is a good example of the problem of externalities, as is putting air filtration systems on factories. When the externality is large and the upfront costs for the investment are sizable in relation to the expected recoverable benefit, a market failure occurs. This market failure means the investment is not made and consumers are made worse off. In the healthcare context, the benefits of costly HIT systems [34] do not produce the necessary incentives for physicians to invest in them. Acquiring and implementing an Electronic Health Record (EHR) system, for example, entails a major financial investment. One study examining such acquisition costs for solo or small group practices estimated that "[i]nitial EHR costs were approximately $\$ 44,000$ per full-time equivalent (FTE) provider per year, and ongoing costs were about $\$ 8,500$ per FTE provider per year." For this reason, only $14 \%$ of physicians have 
minimally functional HIT systems [35]. Solo or singlepartner practices, accounting for about half of all doctors, had the lowest level of comprehensive HIT use- $7.1 \%$ of solo practitioners and $9.7 \%$ of those with a partner [35].

While joint negotiation may increase the costs for physician services in the short term, it will reduce overall system costs in the long term. HIT systems will create efficiencies that will improve care and likely reduce costs. According to the CBO report, HIT has the potential, if adopted widely and used effectively, to save the healthcare sector about $\$ 80$ billion annually (in 2005 dollars) [33]. Thus, gains in the form of market efficiencies, reduced utilization, and increased availability of patient data will offset higher costs for networks to implement HIT. The FTC recognized this in its GRIPA advisory letter:

"Higher unit prices may be of little concern to a customer if they occur within integrated programs that result in lower total costs (e.g., through elimination of unnecessary and inappropriate utilization of services) and higher quality (e.g., better medical outcomes)" [11].

How well HIT lives up to its potential, however, depends in part on how effectively financial incentives are realigned to encourage the optimal use of the technology's capabilities [33]. In the current environment, health insurers, the entities most likely to benefit from cost savings, have demonstrated little interest in implementing these systems and are unlikely to make substantial investments in HIT in the future. Given the expense of HIT implementation and the inability of physicians, the group to which the burden of implementation has fallen, to capture the majority of benefits and returns, physicians should be permitted to negotiate jointly with payors to properly allocate cost savings. Without the ability to recoup some of the expense of these systems by joining a network and achieving increased contracting efficiencies, it will be difficult, if not impossible, for many physicians across the country to make the heavy investments in time and money that the adoption of such a system would require.

Joint contracting is also essential for those physicians in small or solo practices who wish to participate in performance-based payment initiatives. The data and coordination required for these programs is out of reach for the majority of physicians. The FTC in its GRIPA advisory letter recognized this when it noted that implementing a program in which different subsets of physicians are participating in different payor contracts "could interfere with the network's ability to effectively gather data and monitor and evaluate physician performance under the program." Currently, most performance-based payment initiatives are specifically targeted at medical groups or networks rather than small practices. As a Commonwealth Fund study on P4P recently noted:
"Smaller groups generally have few incentives for care coordination, as they usually do not receive payment beyond the evaluation and management fees they are able to bill for acute visits. However, by banding together under the umbrella of organizations, and becoming eligible for performance payments through [the Medicare P4P Demonstration Project] or similar incentive programs, they have more motivation and support for care coordination" [36].

Physicians who predominantly still practice in small groups lack the economic scale. By teaming up in a network, small practices may gain the magnitude for the care coordination, aggregation of data, and purchasing power required for the implementation of these initiatives.

There are several potential strategies to achieve the goal of increased flexibility for physician collaboration. First, it is important that physicians are aware of "clinical integration" and other options the Federal antitrust enforcers have acknowledged as acceptable.

Second, major changes that have taken place in the market since the current FTC enforcement guidelines were drafted. In this regard, the AMA is actively working to have the guidelines revised. AMA has submitted a formal request to the FTC entitled: "Physician Networks and Antitrust: A Call for a More Flexible Enforcement Policy" [37].

Finally, legislation at the federal and/or state level is warranted to encourage physician collaboration. At the federal level, an option that deserves serious consideration is the countervailing market power approach which has been suggested by former Congressman Tom Campbell [38]. Under this proposal, physician groups would be allowed to bargain collectively without fear of violating the antitrust laws to the extent the group had no greater market power than that enjoyed by the health insurer with which it was bargaining. A state is also free to exempt itself from federal antitrust rules by enacting a law which both affirmatively expresses a decision to substitute regulation for a market competition as the best way of achieving a state policy objective, and creates a mechanism ensuring that the state "actively supervises" the resulting conduct to ensure that the state policy objective is indeed being promoted.

\section{Discussion}

In this paper, the writer has argued there is a profound imbalance in the marketplace between the health insurers who collect premiums to pay for medical care and the physicians who provide medical care. Such an imbalance has resulted in an increasingly unfair and inefficient healthcare delivery system. Further, FTC and DOJ 
enforcement policies have led to aggressive antitrust actions primarily against physicians. This has had the counterproductive result of inhibiting the physician community from engaging in the innovative collaborations necessary to take optimal advantage of HIT. Unfortunately, these same agencies have adopted a largely "hands-off" policy towards the health insurers, resulting in the unfettered consolidation of the health insurance industry. The playing field between health insurers and physicians should be leveled to remedy the situation. This will require changes in three major areas: (1) health insurers should be prohibited from engaging in anticompetitive activity; (2) the continuing improper consolidation of the health insurance industry should be curtailed; and (3) the physician community should be freed to undertake the collaborative activity necessary to the establishment of a transparent, coordinated, and efficient delivery system.

Some economists have suggested that increased consolidation of health insurers will lead to increased efficiency and, concomitantly, that federal antitrust enforcement policy has properly prioritized the elimination of physician "cartels." These economists suggest that health insurers, as purchasers of health care services, act as surrogates for consumers, driving down physician reimbursement for the public good.

In this paper, the writer has argued that these economists are wrong.

The evidence suggests that health insurers, as a result of the consolidation of the market, are exercising both monopoly and monopsony power in many communities. These insurers are not sharing with consumers the bulk of the "savings" they have achieved by driving down provider reimbursement levels and in fact may be perversely increasing the cost of care by increasing physician workforce scarcity issues and slowing the adoption of HIT. Given that physician incomes are flat or declining, the continued focus on physician "cartels" seems unwarranted. Additional studies on the connection between health insurance premium increases and the relative consolidation of the health insurance would be helpful to develop a more robust understanding of the health insurance marketplace. Similarly, studies examining the impact of the plethora of FTC and DOJ enforcement actions against physicians would be helpful to understand whether these prosecutions have ultimately benefited the salient patient populations.

Importantly, the healthcare antitrust landscape has changed. This environment is very different from the early 1980s when the U.S. Supreme Court decided Maricopa. The lack of opportunities for physicians to collaborate on important initiatives must be reexamined and revisedeither through judicial, administrative or legislative activity. As the increasingly inadequate supply of physicians demonstrates, the status quo is not sustainable. To achieve a truly efficient healthcare delivery system capable of meeting the challenges of the 21 st century, including the demands of an increasing Medicare population, the physicians who provide the care must be allowed-and encouraged - to collaborate and innovate as critical participants in the healthcare marketplace.

Acknowledgments I thank Kevin Bozic, M.D. for organizing the symposium and for his encouragement in writing this article, and Catherine I. Hanson, J.D., Henry Allen, J.D., Wesley Cleveland, J.D., and Michaeal R. Bernstein, J.D. for their review and comment.

Open Access This article is distributed under the terms of the Creative Commons Attribution Noncommercial License which permits any noncommercial use, distribution, and reproduction in any medium, provided the original author(s) and source are credited.

\section{References}

1. Reiter v. Sontone Corps, 442 US 330 (1979) (quoting R. Bork, The Antitrust Paradox 66 [1978]).

2. NCAA v Board of Regents of Univ. of Okla, 468 US 85 107-09 (1984).

3. Weyerhaeuser v Ross - Simmons Hardwood Lumber Co., Inc, 549 US 312 (2007).

4. Goldfarb v. Va. State Bar, 421 U.S. 773, at p. 787 (1975).

5. Arizona v. Maricopa County Medical Society, 457 U.S. 332 (1982).

6. Broadcast Music, Inc. v. CBS, 441 U.S. 1 (1979).

7. US Department of Justice, Antitrust Division, and Federal Trade Commission, Statements of Antitrust Enforcement Policy in the Health Care Area (15 September 1993).

8. US Department of Justice \& Federal Trade Commission, Statements of Antitrust Enforcement Policy in Health Care (Aug. 1996). Available at: http://www.usdoj.gov/atr/public/guidelines/ 1791.htm or www.ftc.gov/bc/healthcare/industryguide/policy/ hlth3s.pdf. Accessed August 27, 2009.

9. Letter from Jeffrey W. Brennan, Asst. Director, Bureau of Competition, to John J. Miles (Feb. 19, 2002).

10. Letter from Markus H. Meier to Christi J. Braun and John J. Miles (Sept. 17, 2007).

11. NCAA v. Board of Regents of the Univ. of Oklahoma, 468 U.S. 85 (1984).

12. Antitrust Guidelines for Collaborations among Competitors (April 2000) ("Competitor Collaboration Guidelines") at $§ 3.2$.

13. United States v. South-Eastern Underwriters Association, 322 U. S. 533 (1944).

14. U.S. Dep't of Justice \& Federal Trade Comm'n, Horizontal Merger Guidelines $\S 0.1$ (1992 rev. 1997, efficiencies section only) [hereinafter Merger Guidelines]. Available at: http://www. ftc.gov/bc/docs/horizmer.htm. Accessed August 27, 2009.

15. The Health Care Acquisition Report Fourteenth Edition, 2008. Norwalk, CT: Irving Levin Associates, Inc; 2008.

16. American Medical Association. Competition in Health Insurance: A Comprehensive Study of US Markets: 2008 Update. Available at: http://www.ama-assn.org/ama/noindex/advocacy/ 9573.shtml. Accessed August 27, 2009.

17. American Medical Association. Competition in Health Insurance: A Comprehensive Study of US Markets:/ 2007 Update. Available at: http://www.ama-assn.org/ama1/pub/upload/mm/368/ compstudy_52006.pdf. Accessed August 27, 2009. 
18. The Kaiser Family Foundation and Health Research Educational Trust. Employer Health Benefits: 2008 Summary of Findings. Available at: http://ehbs.kff.org/. Accessed August 27, 2009.

19. The Kaiser Family Foundation and Health Research Educational Trust. Employer Health Benefits 2006 Summary of Findings. Available at: http://ehbs.kff.org/. Accessed August 27, 2009.

20. Chernew M, Cutler D, Keenan P. Increasing health insurance costs and the decline in insurance coverage. Health Serv Res. 2005;40:1021-1039.

21. Hammer PJ, Sage WM. Monopsony as an agency and regulatory problem in health care. Antitrust Law J. 2004;71:949-988.

22. Tu HT, Ginsburg PP. Losing ground: physician income, 19952005. Center for Studying Health System Change Tracking Report No. 15. 2006.

23. Robinson JC. Consolidation and the transformation of competition in health insurance. Health Aff. 2004;23:11-24.

24. United States v. Aetna, Revised Competitive Impact Statement, Civil Action 3-99CV1398-H (N.D.Tex, 1999). Available at: http:// www.usdoj.gov/atr/cases/f2600/2648.htm. Accessed August 27, 2009.

25. United States v. UnitedHealth Group Inc., Case No. 1:05CV0 2436 (D.D.C. Dec. 20, 2005). Available at: http://www.usdoj. gov/atr/cases/f213800/213815.htm. Accessed August 27, 2009.

26. Association of American Medical Colleges. The Complexities of Physician Supply and Demand: Projections Through 2025. Available at: https://services.aamc.org/Publications/showfile.cfm? file=version 122.pdf\&prd_id=244\&prv_id=299\&pdf_id=122. Accessed October 31, 2008.

27. Salsberg E, Grover A. Physician workforce shortages: implications and issues for academic health centers and policymakers. Acad Med. 2006;81:782-787.
28. Association of American Medical Colleges. AAMC Statement on the Physician Workforce, June 2006. Available at: http://www. aamc.org/workforce/workforceposition.pdf. Accessed October 31, 2008.

29. Pham H, Ginsburg P. Unhealthy trends: the future of physician services, Health Aff. 2007;26:1586-1598.

30. Rosenthal M, Landon B, Howitt K, Song HR, Epstein AM. Climbing up the pay-for-performance learning curve: where are the early adopters now? Health Aff. 2007;26:1674-1682.

31. Rosenthal MB, Dudley RA. Pay-for-performance: will the latest payment trend improve care? JAMA. 2007;297:740-744.

32. Easterbrook F. Maximum price fixing. 48 U. Chi. L. Rev. 886, 898-899 (1981).

33. Congressional Budget Office. Evidence on the costs and benefits of health information technology. May 2008:19-20.

34. Miller RH, West C, Brown TM, Sim I, Ganchoff C. The value of electronic health records in solo or small group practices. Health Aff. 2005;24:1127-1137.

35. Office of National Coordinator for Health Informational Technology (July 2007).

36. Trisolini M, Pope G, Kautter J, Aggarwal J. Medicare physician group practices: innovations in quality and efficiency. The Commonwealth Fund. 2006. Available at: www.commonwealth fund.org/usr_doc/971_Trisolini_Medicare_physician_group_ practices_i.pdf. Accessed August 27, 2009.

37. American Medical Association. Physician Networks and Antitrust: A Call for a More Flexible Enforcement Policy. Available at: http://www.ftc.gov/bc/healthcare/checkup/pdf/AMAComments. pdf. Accessed August 27, 2009

38. Campbell T. Bilateral Monopoly in Mergers, 74 Antitrust L.J. 521 (2007). 